\title{
Cultura, cidadania e patrimônio cultural: interfaces entre a escola, a cidade e as políticas culturais na cidade de Guararema, SP
}

\author{
Francisco Carlos Franco* \\ Rosália Maria Netto Prados** \\ Luci Mendes Bonini***
}

\section{Resumo}

O presente texto aborda a questáo do patrimônio material e imaterial e seu potencial educativo na formação cidadá de alunos da educaçáo básica. Tem como objetivo refletir sobre as perspectivas de desenvolvimento de uma Educação Patrimonial em uma cidade educadora. Fundamenta essa discussáo estudos que analisam a educação sob uma perspectiva crítica, em que esta supere a simples transmissáo e contemplação dos bens patrimoniais destituídas de sentido, presentes em muitas propostas educativas em instituiçóes de educação formal e não formal, de modo, ainda, que haja colaboração com a gestão do patrimônio cultural. Sendo assim, este texto contempla reflexóes sobre a educação patrimonial como uma área emergente na educação e analisa uma experiência na regiâo do alto Tietê, no município de Guararema. Os primeiros resultados apontam para consideraçóes de que a Educação Patrimonial deve ser um diálogo permanente entre as vivências, experiências e percepçóes dos educandos e cidadãos ante os bens culturais e suas formas de ser e de agir cotidianos, com os conteúdos escolares e açóes educativas desenvolvidas nas unidades escolares e instituiçóes culturais, como forma de entender os processos constituintes de sua identidade cultural auxiliando na gestão do patrimônio cultural.

Palavras-chave: Educação Patrimonial. Cidade Educadora. Patrimônio Cultural.

* Doutor em Educação pela Pontifícia Universidade Católica de São Paulo (PUC/SP). Professor do Curso de Pedagogia e do Programa de Mestrado em Políticas na Universidade de Mogi das Cruzes (UMC) e dos Cursos de Formação de Professores na Universidade Braz Cubas (UBC). ** Doutora em Semiótica e Linguística Geral pela Universidade de São Paulo (USP). Professora do Programa de Mestrado em Políticas Públicas na Universidade de Mogi das Cruzes (UMC), da Faculdade de Tecnologia do Centro Estadual de Educaçáo Tecnológica (FATEC) e do Curso de Letras das Faculdades Bandeirantes de Suzano (UNISUZ).

*** Doutora em Comunicação e Semiótica pela Pontifícia Universidade Católica de São Paulo (PUC/SP). Professora da Universidade de Mogi das Cruzes (UMC). 


\section{Introdução}

Vivemos um momento de mudanças significativas que se intensificaram com a crise do socialismo e a ofensiva do capitalismo (PAULO NETTO, 2012, p. 9), e com o processo de globalização que se expandiu de forma intensa, a partir últimas décadas do século $\mathrm{XX}$, o que proporcionou impactos econômicos e políticos com graves consequências, inclusive para os patrimônios culturais materiais e imateriais; os primeiros desaparecem para dar lugar a empreendimentos em nome do progresso, os segundos que se desvanecem em consequência do etnocídio provocado pela grande mídia, vejam-se as ideias deixadas por pensadores como McLuhan (1964) que previra este nivelamento.

Em toda a América Latina, incluindo-se aí o Brasil, a educação para a preservação de bens culturais nunca foi prioridade, já que saúde, educação, habitação e outras políticas sociais nem chegaram ainda a proporcionar maiores resultados.

Os discursos que apregoam a igualdade, a acessibilidade enfim, os direitos universais parecem estar mais ligados à construção da democracia do voto e não a uma justiça social, até porque, historicamente, no continente latino-americano as democracias são muito jovens e a responsividade pública ainda é pouco estimulada.

Nesse contexto, várias atitudes e posturas que permeiam a vida cotidiana em nossas cidades foram se consolidando. O consumo desenfreado, a competição, o individualismo e a solidão que conduziram, por sua vez, a uma decadência na qualidade de vida e na convivência entre as pessoas, o que se percebe nas manifestaçóes, cada vez mais frequentes, sobre preconceitos raciais, de gênero, de poder econômico, de crença, de idade e de orientação sexual.

Além disso, também vivemos um momento do aumento da agressividade e da banalização da violência e de manifestaçôes, também mais frequentes, de doenças e síndromes, consideradas como fruto do mundo pós-moderno e o trancafiamento da burguesia em condomínios ou habitaçóes fortificadas, reduzindo, assim, as chances da cumplicidade social que há ao redor dos patrimônios culturais. Estes sempre foram um espaço de construção de significados de uma comunidade.

Neste momento, em que se dão os distanciamentos dos sujeitos desse convívio, a educação patrimonial torna-se uma área emergente, que muda as formas de se valorizar o patrimônio e ao mesmo tempo auxilia na gestáo 
das políticas culturais, movimentos de preservação do patrimônio cultural e de outras memórias vêm ganhando força política na sociedade de consumo (MENESES, 1992).

Dessa forma, os olhares se voltam para a educação como uma via para propiciar uma educação cidadã às novas geraçóes, sendo o espaço da escola de educação básica um dos mais solicitados para abordar questóes iminentes e presentes no mundo contemporâneo, ampliando de forma significativa as responsabilidades da escola e dos profissionais que nela atuam, principalmente sobre a preservação das tradições culturais, incluindo-se aí patrimônio material e imaterial.

Neste estudo, fundamentamos teoricamente a emergência da Educação patrimonial e suas interfaces entre a escola, a cidade e as políticas culturais, Educação patrimonial na educação formal, Educação patrimonial e a educação não formal, e descrevemos o projeto Guararema Cidade Natal, que pode ser inserido no campo da Educação Patrimonial e formação cidadã. É um projeto desenvolvido desde 2009 na cidade de Guararema, do estado de Sáo Paulo, região do Alto Tietê, e tem como objetivos não só a promoção e educação do e para o turismo, mas também a preservação do meio ambiente. Em virtude do interesse dos pesquisadores sobre patrimônio cultural e as políticas culturais encontradas na região do Alto Tietê, chamou a atenção, uma apresentação da Secretária de Cultura do Município de Guararema, durante o II Seminário de Políticas Públicas, evento promovido em 2013, na Universidade de Mogi das Cruzes (UMC), São Paulo.

Assim, traçou-se como objetivo central: discutir a educação patrimonial como um campo emergente na gestão dos patrimônios culturais. As questóes que emergem neste percurso são: como se dá a educação patrimonial no Brasil e no mundo? Sob qual paradigma se abriga a gestão cultural? É possível realizar uma abordagem sobre o patrimônio cultural a partir de uma perspectiva da sustentabilidade? Como ocorre a gestáo do patrimônio cultural nas cidades brasileiras?

O método de levantamento dos dados foi a análise documental de vídeos da rede social YouTube, páginas de usuários da rede social Facebook, do poder local sobre o projeto, além de levantamento bibliográfico sobre políticas culturais (MENESES, 1992; PELEGRINI, 2009; TURINO, 2010) e educação e educação patrimonial (CABEZUDO, 2004; CHAUÍ, 2006; OLIVERIA; WENCESLAU, 2007; VALECILLO, 2009; MELO; BONINI, 2012). 
Os resultados obtidos até o momento demonstram que algumas cidades brasileiras vêm incorporando na gestão cultural açôes que, por sua vez, integram a preocupação com a sustentabilidade e com a preparação das geraçóes futuras para a conscientização da finitude dos bens materiais, ambientais e culturais do planeta, para o auxílio da preservação de bens culturais e manutenção da identidade local, e, consequentemente, fortalecer a economia do município.

\section{Educação patrimonial}

Valecillo (2009) afirma que a educação patrimonial é uma área emergente na educação, principalmente porque a sociedade do espetáculo, do efêmero vai anulando lentamente as manifestações culturais de uma comunidade. É necessário criar consciência na população, por meio da educação, para uma mudança nas formas como se vê o patrimônio cultural. Despertar um sentimento de pertencimento maior e uma forma de compreender que bens culturais trazem valores agregados, tais como o sentimento de identidade de uma comunidade e valores econômicos, pois incentiva o turismo.

Desde a década de 1980 mudanças curriculares e projetos educativos foram instituídos em nosso país, com o objetivo de ampliar o debate e implantar mudanças frente a questóes relevantes ligadas aos problemas sociais, à crise de valores e às novas formas de compreender a educação escolar, que evidenciou a necessidade de uma mudança radical, passando da simples transmissão de dados e informaçóes, para um processo educativo que prime em desenvolver habilidades e competências que possibilite aos educandos selecionar as informaçôes e transformá-las em conhecimento.

Meneses (1992) afirma que a memória precisa ser resgatada, preservada e restaurada e, para esse registro/resgate do passado, depende-se de valores cultivados no presente que indicam o que deve ser preservado, e as políticas culturais atuais vêm atribuindo esses valores, e, nesse compasso, ainda que ela está sujeita à dinâmica social, e a atual classifica a memória como mercadoria.

Por mais bem intencionadas que sejam estas e outras açóes implantadas nas políticas públicas para a educação básica em nosso país nos âmbitos nacional, estadual e municipal, com algumas propostas pertinentes e consequentes, o seu impacto nas mudanças desejadas podem se tornar ínfimos se não forem acompanhadas por açóes que contemplem as diversas dimensóes que constituem a realidade. 
Gómez-Granell e Vila (2004, p. 12) destacam a necessidade de se ampliar os tempos, espaços e atores para proporcionar uma educação integral, uma vez que as instituiçóes escolares têm limites no impacto formativo de suas açôes educativas, que comumente não estão em consonância com as atitudes, comportamentos, valores e preceitos presentes nas vivências e experiências com que os educandos convivem.

Não é raro verificarmos que propostas educativas desenvolvidas nas unidades escolares, como as voltadas para o estudo do meio ambiente, valores, educação para a paz etc., que visam a propiciar aos alunos uma educação crítica e sensível, orientadas por princípios éticos e de valorização da vida comunitária, estarem em desacordo com a realidade que os educandos estão expostos no bairro, na cidade em que moram, ou pelos meios de comunicação de massa, presenciando com frequência atitudes antiéticas, de violência, de desrespeito ao meio ambiente, de incentivo ao consumismo, individualismo e competitividade, entre outras situações, sendo algumas dessas ações promovidas pelos próprios órgãos públicos (GÓMES-GRANELL; VILA, 2004, p. 30).

Os valores da igualdade que prevalecem na sociedade são sempre aqueles da lógica do consumo e do mercado do entretenimento que hipocritamente desenham padróes estéticos, morais e de felicidade, sempre baseados na lógica do consumo, eliminando-se a beleza da diversidade e da percepção do mosaico cultural que se configura o Brasil.

Tal realidade demanda uma nova forma de se pensar a educação na cidade com o objetivo de favorecer uma formação cidadã às novas geraçóes, ampliandose e potencializando os tempos, espaços e recursos presentes nos espaços urbanos, o que já é uma realidade desde o final do século XX, nas chamadas "cidades educadoras", experiência essa que se orientou em duas direçóes:

[...] por um lado, os cidadãos começaram a se associar para enfrentar problemas sociais pendentes, criando redes de organizaçóes não-governamentais, com um crescente envolvimento e com a participação de inúmeros voluntários; e, por outro lado, a partir do engajamento de prefeituras com maior sensibilidade educativa, esses movimentos cidadãos foram aceitos e integrados, além de intensificados e ampliados, com uma consciência clara da valiosa contribuição educadora e de vertebração da comunidade que deles podemos esperar. (GRANELL; VILA, 2004, p. 12). 
No entanto, é preciso destacar que uma cidade educadora que vislumbre outras formas de educação informal e não formal não enfraquece o trabalho da escola, pelo contrário, potencializa e reafirma seu papel histórico e intransferível na formação das novas geraçóes, visto que é na escola que o conhecimento é sistematizado. Assim, a escola se apresenta como local para organizar algumas aprendizagens que ainda estão dispersas, como também para refletir, criticar e relacionar as aprendizagens estimuladas pelos diversos agentes de educação não formal em uma perspectiva interdisciplinar, além de apresentar múltiplas possibilidades de mediação educativa proporcionada pela escola, explorando e ampliando o conhecimento da cidade e a comunidade local por meio de visitas a espaços públicos de cultura, lazer, esportes, entre outros.

Dessa maneira, a educação formal e não formal trabalhadas em conjunto ampliam as aprendizagens ao estabelecer um diálogo entre o mundo vivido, os espaços urbanos e as experiências náo escolares, aos processos educativos desencadeados na escola, em consonância com a vida e a organização cultural e espacial da cidade.

A educação patrimonial não pode divorciar-se dos parâmetros globais e locais da educação, segundo Delors (apud VALECILLO, 2009, p. 274):

Desde finales del siglo XX la UNESCO ha elaborado varios documentos donde propone nuevos alcances para la educación. Donde ésta se concibe como un proceso para toda la vida y un instrumento que permitirá alcanzar los ideales de paz, libertad y justicia social, donde los ciudadanos aprendamos a vivir juntos con nuestras diferenciais y buscar el diálogo.

A partir deste pensamento, entende-se que a educação patrimonial como área de conhecimento está incluída na noção do viver juntos, da liberdade e da justiça social. Há que se criar estratégias educativas para a resolução de problemas comuns entre os cidadáos, principalmente nas questóes culturais que são construções coletivas.

\section{Educação patrimonial: interfaces entre a escola, os atores sociais e as políticas culturais}

São várias as culturas que possibilitam uma formação cidadã às crianças, aos jovens e aos adultos que frequentam a educação formal, que, de forma 
integrada, vão constituindo um universo de significaçôes que se apresentam como importantes referências para a constituição das formas de ser e de agir, em diálogo permanente com os tempos, espaços e recursos com os quais convivem e de que fazem parte.

Entendendo a cidade, em seu potencial educador, é desejável que se ampliem as açóes educadoras existentes no espaço urbano além do âmbito da educação formal, com vistas a propiciar vivências e experiências que intensifiquem o desenvolvimento de uma postura crítica e sensível ante o ordinário, que prima em se orientar por movimentos de manutenção e de permanência acrítica do instituído.

Acreditamos que a formação nos espaços formais e não-formais têm o potencial em desenvolver aprendizagens mais significativas, por meio de uma postura crítica, reflexiva, emotiva ante o estabelecido, com o intuito de conhecer suas contradições e se opor a qualquer forma de dominação, domesticação e desumanização. É entender a educação como uma forma de, por meio da construçáo do conhecimento permeado pelos conteúdos e saberes historicamente construídos, entender o mundo como uma possibilidade, não como uma coisa pronta, imutável.

Dessa forma, educar transcende uma mera transmissão do conhecimento com a perspectiva de uma simples aplicabilidade futura no mercado de trabalho, ou seja, uma educação que se organiza fundamentada em uma racionalidade técnica. Pelo contrário, é vislumbrar o processo educativo que vai além de acessar dados e informaçóes, que favoreça o questionamento da consistência e coerência das coisas, das organizaçôes, das relações entre humanos e desses com o meio social e físico, das questóes de poder e do capital e das consequências na vida das pessoas, entre outros.

É segundo esses princípios que defendemos uma Educação Patrimonial, entendendo-a em uma perspectiva crítica de uma pedagogia urbana em uma cidade educadora. Compreende o estudo, a reflexão, a organização de tempos, espaços e recursos referentes ao patrimônio material e imaterial nos centros escolares, nas instituições artísticas e culturais etc., como também nos sentimentos, representaçôes, valores, ideias, entre outros, partilhados e validados como referências para a vida em comunidade.

Assim, fazem parte deste campo de estudo os patrimônios materiais e imateriais, sendo, segundo Pelegrini (2009, p. 28), os materiais constituídos 
pelos bens tangíveis, que englobam vários bens móveis, como objetos de arte, acervos museológicos, documentais, partituras, adereços etc., e os bens imóveis, que são compostos por edificaçóes, templos, sítios paisagísticos e arqueológicos, monumentos, entre outros. Já, os patrimônios imateriais, considerados como bens intangíveis, são as ideias, costumes, danças, crenças, casos, festas, modos de vida etc.

Seu estudo, em uma perspectiva crítica, visa romper com o "olhar ingênuo", de senso comum, pois intenciona desenvolver:

[...] a capacidade de decifrar as formas de produção social da memória e do esquecimento, das experiências, das ideias e dos valores, da produção das obras de pensamento e das obras de arte e, sobretudo, é a esperança racional de que essas experiências e ideias, desses valores e obras surjam um sentido libertário, com força para orientar novas práticas sociais e políticas das quais possa nascer outra sociedade. (CHAUÍ, 2006, p. 9).

Nessa concepção, a Educação Patrimonial apresenta-se como uma forma de superar a tendência hegemônica presentes nos âmbitos da educação e da cultura em nosso país, que se impóe como:

[...] uma direção geral (política e cultural) da sociedade, um conjunto articulado de práticas, ideais, significaçóes e valores que se confirmam uns aos outros e constituem o sentido global da realidade para todos os membros de uma sociedade, sentido experimentado como absoluto e único e irrefutável, porque interiorizado e invisível como o ar que se respira. (CHAUI, 2006, p. 22).

Entretanto, uma proposta de Educação Patrimonial, ao se propor a superação dos processos de homogeneização cultural, também se apresenta como uma forma de, por intermédio do estudo do passado, compreender e ressignificar o presente, pois:

A história permite estabelecer relaçóes entre os costumes e valores integrantes de nossa trajetória coletiva com outros processos históricos e com elementos formadores da história de cada um. Trata-se de um espaço de 
pertencimento, no qual a modernidade não consiste em começar tudo de novo, iniciar do nada, mas em sentirse enraizado, pertencendo, apropriando e reelaborando a herança das geraçóes anteriores. $\mathrm{O}$ grande e necessário desafio é ser moderno a partir dos legados que nos formam, legitimando a contemporaneidade. (SETUBAL; ÉRNICA, 2006, p. 143).

Um trabalho voltado para o patrimônio cultural objetivando desvelar e significar a heterogeneidade, em contraponto à perspectiva hegemônica, como também para conhecer e ressignificar o processo histórico e os sentidos presentes no patrimônio material e imaterial, possibilita uma aproximação e apropriação crítica da pluralidade de culturas presentes nos bairros, nas comunidades, nas cidades etc. Permite um processo em que o educando se reconheça como sujeito, que habita um espaço com múltiplas manifestações, objetos, edificaçóes, ideias etc., que foram se instituindo em diversas épocas, sob influências e concepçôes distintas, que interferem em suas formas de ser, pensar e de agir.

Para tanto, é preciso reconhecer o viés ideológico presente em vários espaços, objetos, representaçóes, manifestações, entre outros, do patrimônio cultural, impostos e validados em sua significância pelos poderes políticos, econômicos e/ou religiosos, e:

[...] tornar visível a disputa pela memória social, deixando aparecer suas açóes até então invisíveis, capazes de questionar as significaçóes institucionalizadas com que a sociedade constrói para si mesma seu próprio significado. Por isso mesmo, trata-se de uma prática reflexiva sobre a concepção de patrimônio histórico, cultural e ambiental. (CHAUÍ, 2006, p. 124).

Porém, como destaca Chauí (2006), temos duas posturas que dificultam uma Educaçáo Patrimonial crítica: uma que apresenta a cultura como um saber de especialistas, que só a compreende pessoas que têm uma formação específica para fruí-la; e outra que afasta grande parte da população que, nas raras oportunidades que têm de acesso aos bens culturais, assumem uma postura passiva perante o lazer e o entretenimento que lhes é oferecido.

Por isso, o processo educativo crítico, que defendemos no que se refere ao patrimônio cultural, só se efetivará se tivermos políticas públicas culturais 
e educacionais que promovam aproximaçóes significativas dos educandos no intuito de democratizar o acesso dos bens culturais por meio de uma ação educadora produtora de sentido, tendo a escola como uma das instâncias para sua viabilização, além de propostas educadoras em espaços com potencial educativo não-formais, promovidas por instituiçôes que trabalham direta ou indiretamente com o patrimônio cultural.

\section{Educação patrimonial na educação formal}

Oliveira e Wenceslau (2007, p. 30) destacam que a Educação Patrimonial no âmbito escolar deve ter uma abordagem que vise ampliar o conhecimento e os sentidos referentes ao patrimônio histórico, cultural ou natural, que serve de subsídio para que as pessoas despertem o interesse e dele se aproximem. Tem como objetivo principal a conscientização como forma de resgate e valorização de uma identidade local, regional ou nacional.

Embora relevante nos processos educativos na educação formal, a Educação Patrimonial não deve ser trabalhada de forma impositiva de uma identidade, uma obrigação, mas , sim, abordada como um estímulo,

[...] um ponto de partida, apresentando, discutindo e gerando, em cada indivíduo, a necessidade, o interesse em querer identificar-se com o patrimônio, apenas apresentando subsídios para que ele veja dentro de sua comunidade os patrimônios que são significativos de sua identidade. (OLIVEIRA; WENCESLAU, 2007, p. 31).

Reportando-se às particularidades, ideias, objetos e edificações de uma comunidade, de uma cidade, regiáo, a Educação Patrimonial assume papel fundamental na superação da perspectiva hegemônica e da cultura de massa imposta na sociedade pós-moderna, sendo um contraponto à fluidez, inconstância e superficialidade presentes e incentivadas pela sociedade do consumo. Assim entendida, a Educação Patrimonial crítica na escola favorece a reflexão, a valorização, a permanência de sentidos relevantes que permeiam o patrimônio material e imaterial, além de favorecer sua conservação para fruição das futuras geraçóes de sua herança cultural.

Porém, alguns cuidados devem ser observados, uma vez que, como postulam Oliveira e Wenceslau (2007, p. 32), a Educação Patrimonial não visa 
apenas a estimular a conservação e a permanência de espaços físicos e objetos culturais, como edificaçóes, praças, monumentos etc., ou de manifestaçóes, como festas, indumentárias etc., mas também a resgatar a memória, os sentidos que levam uma determinada comunidade a reconhecer estes elementos como patrimônios legítimos de um coletivo que com ele se identifica. Nessa perspectiva, esta Educação na escola tem como objetivo: “[...] resgatar a relação de afeto ente a comunidade e seus patrimônios, estabelecendo entre eles um processo de aproximaçáo fazendo com que a comunidade tenha um sentimento de pertencimento em relação aos seus patrimônios, desejando, assim, seu resgate e preservação" (OLIVEIRA; WENCESLAU, 2007, p. 32).

Para isso, é preciso que a escola contemple a questão patrimonial desde a elaboração de seu projeto político-pedagógico, até o desenvolvimento de práticas educativas que transcendam a simples observação do patrimônio cultural de forma passiva e contemplativa, para simples assimilação e conhecimento. É nesse sentido que os princípios de cidade educadora nos auxiliam a vislumbrar uma pedagogia crítica ante o patrimônio cultural, visto que não o considera como processos educativos isolados nas instituiçóes escolares, pois prima em entendêlos em diálogo permanente com a regiáo, a cidade, os bairros e comunidades, como forma de apropriação das pessoas e em sua participação nas propostas referentes aos espaços em que vive.

Uma ação educativa crítica na escola, que se organize por estes preceitos, supera o viés do conhecimento estático e de simples assimilação acrítica, para uma postura crítica, sensível e criativa, pois incentiva a participação e a corresponsabilidade para com os bens culturais e patrimoniais, visto que "[...] descobrir e conhecer bem a cidade e estudá-la como enquadramento de referência dos problemas globais e possíveis soluçóes. Neste sentido, torna-se necessário considerar a cidade como um mundo por descobrir, por utilizar" (VILLAR, 2007, p. 40).

Tais princípios apontam para a construção de metodologias que proporcionem a superação de uma olhar de senso comum diante do patrimônio cultural, uma proposta educativa que desperte uma sensibilização desse rico universo, para que o educando entenda-o como um conjunto de significaçóes constituintes no espaço urbano local em que vive, ou que de alguma maneira interfere nas suas formas de ser e agir individual e do coletivo com que está relacionado.

Pérez Gómez (2001) entende a escola como o local em que há o cruzamento de culturas, entre as quais se destaca a cultura experencial, que é 
reflexo de uma cultura local, que se constitui por intermédio de aproximaçôes empíricas em elaboraçóes superficiais, acríticas. Entretanto, apesar de estarem ancoradas por esquemas de pensamento e açóes fragmentadas, e, em algumas situações, com lacunas, equívocos, contradiçôes, mitos, preconceitos etc., demonstram-se como uma "[...] plataforma cognitiva, afetiva e comportamental sobre a qual assentam interpretaçóes acerca da realidade, seus projetos de intervenção, seus hábitos essenciais e seus comportamentos cotidianos" (PÉREZ GÓMEZ, 2001, p. 205).

$\mathrm{O}$ autor considera a cultura experiencial como um processo ligado à interação do indivíduo com o mundo vivido, os esquemas de interpretação que estabelecem entre a cultura local e a individual na construção social de significados.

Dessa maneira, as vivências, as experiências e os sentidos de uma aproximação, ainda que empírica, são aspectos relevantes em uma ação educativa que reverencie o patrimônio cultural pela interação da cultura acadêmica (PÉREZ GÓMEZ, 2001), com os conteúdos a este relacionados, com a realidade social do educando e suas leituras que fazem do mundo, que, “[...] pela intervenção do professor e por sua própria participação ativa, passa de uma experiência inicialmente confusa e fragmentada (sincrética), a uma visão mais sintética, mais organizada e unificada" (LIBÂNEO, 1999, p. 39).

Todos esses aspectos evidenciam a importância em se estabelecer metodologias que intensifiquem o desenvolvimento de açóes educadoras ligadas ao patrimônio cultural nas escolas. Entre várias possibilidades destacamos a proposta metodológica defendida por Horta $(1999$, p. 6), que se estrutura em quatro etapas:

- A observação - momento em que se refere ao que está sendo visto, com formulação de questóes sobre o objeto em questão com o objetivo de levantar dados e informaçóes para identificar os objetos, saberes ou rituais da comunidade, cidade etc.;

- O registro - dos bens levantados e apontados como relevantes. Nesta etapa os educandos demonstram, por meio de diversas linguagens e estratégias, o valor patrimonial dos estudos realizados na etapa anterior, o que pode ser concretizado por descriçóes escritas ou orais, desenhos, fotografias, maquetes etc.;

- A exploração - análise crítica do patrimônio levantado; etapa que envolve a reflexão, debates, questionamentos, avaliações, utilizando 
fontes diversas para seu aprofundamento sobre o tema em destaque, por intermédio de pesquisas em bibliotecas, sites, jornais, revistas etc.;

- Apropriação - é o momento em que os sentidos e significados emergem, ampliando a percepção, reconhecimento e validação (ou não) do patrimônio em foco.

A Educação Patrimonial na escola é essencial para que o aluno organize e se aproprie deste rico universo, mas é fundamental que os educandos tenham oportunidade de visitar espaços de seu bairro, de sua comunidade, de sua região, para que tenham contato direto com as obras, edificaçóes etc., com reconhecido valor artístico, histórico, cultural e social de diferentes épocas, estilos e culturas.

A visitação a espaços culturais requer um planejamento, para que os alunos possam usufruir o máximo que o espaço/objeto oferece. $\mathrm{O}$ acesso a esses locais possibilita a aproximação do educando à expressividade e ao valor cultural de bens e espaços presentes em sua comunidade, mas que ainda não foram objeto de reflexão e de crítica, como também de objetos e edificações que comumente não fazem parte de sua vida cotidiana.

Todavia, o estudo e as visitas com foco no patrimônio cultural têm de fazer parte de um processo educativo que se articule com os processos de ensino-aprendizagem desenvolvidos na escola. Quando uma visita é proposta de forma desarticulada, apartada das açóes educadoras desencadeadas no espaço escolar, dificilmente os alunos irão entender o sentido da proposta e dos objetos/ representaçôes que irão contemplar.

Também é importante considerar que a articulação entre o trabalho educativo na educação formal em uma cidade educadora, exige um sistema mais amplo que favoreça o diálogo, a vinculação com outros agentes educativos não-formais, em nosso caso, com instituiçóes, espaços e manifestações presentes na comunidade, no bairro, na cidade, democratizando o acesso e a fruição do patrimônio cultural, proporcionando aos educandos uma formação cidadá.

\section{Educação patrimonial e a educação não formal}

A cidade já é, por si só, um espaço em que a diversidade se apresenta composta por diversas culturas constituídas em épocas e locais distintos, sobre concepçóes e ideias que revelam formas de ser e de agir, segundo as quais se estruturam. Mas a cidade é também o local em que se efetiva uma construção 
cultural cotidiana, em que novas representaçóes vão configurando novas significaçóes e sentidos, que nem sempre são incorporados de forma consciente, mas que moldam comportamentos, apresentando-se como importantes referências individuais e coletivas.

Ao se reportar à questáo da identidade cultural que emerge a partir de meados do século XX, Hall (2006, p. 32) afirma que "Entendemos, aqui, a figura do indivíduo isolado, exilado ou alienado, colocado contra o pano de fundo da multidão ou da metrópole anônima e impessoal”.

$\mathrm{O}$ autor considera que, com o processo de globalização, as identidades globais estão enfraquecendo as culturas nacionais, tamanha a infiltração cultural, tendência essa que denomina de "pós-modernidade global", que unifica o consumo e que traz várias consequências, entre elas: " $\mathrm{Na}$ medida em que as culturas nacionais tornam-se mais expostas a influências externas, é difícil conservar as identidades culturais intactas ou impedir que elas se tornem enfraquecidas através do bombardeio e da infiltração cultural" (HALL, 2006, p. 74).

Quanto mais a vida cotidiana é permeada pelo consumo, pelo que Hall (2006) chama de "supermercado cultural", as identidades que se amparavam nas distinçóes culturais locais passaram a se homogeneizar.

Essas questóes, além de tantas outras, reforçam a necessidade e a relevância em implantar políticas públicas no âmbito da cultura que se oriente de forma contra-hegemônica, seja pela superação da sociedade do consumo e do espetáculo, como também da tendência de homogeneização de políticas nacionais apoiadas pela legitimação e fortalecimento de formas de poder, que oculta a divisão de classes, como um sistema abstrato de representaçóes, normas, crenças e valores que pretendem produzir uma ilusória unidade, que se impóe como universal.

Apesar de termos vários expoentes ilegítimos, que são valorizados de forma impositiva de uma cultura, como uma maneira de dominação, temos vários patrimônios que se apresentam de forma legítima e de relevância para uma cultura local, regional ou nacional, que estão presentes em edificaçóes, obras de arte, monumentos, obras literárias etc. Chauí (2006, p. 122) considera as obras de arte e as de pensamento como importantes referenciais identitários de uma cultura, uma vez instituem campos de pensamento e de criação que não existiriam sem estas representaçóes, porque desencadeiam novas ideias, 
pensamentos e produçóes. Sendo assim, a obra se apresenta como uma possibilidade de produção, um recriar, reinventar, sinalizando no presente uma construção futura.

Entender as obras de arte e de pensamento como expressão e sentido, que revelam sentimentos, emoçóes, conflitos, visóes táo diversas sobre o mundo, a sociedade e o ser humano, é vislumbrar um potencial educador nelas presente, por isso, "é preciso ir ao museu e à biblioteca como ali vão artistas e pensadores, para participar de lutas e aventuras, das venturas e desventuras, dos infortúnios e glórias do trabalho, da criação e da descoberta, da retomada do passado para invenção do futuro" (CHAUÍ, 2006, p. 122).

Tais questões apontam a necessidade de se organizar o patrimônio cultural das cidades para democratizar o acesso e proporcionar a todos uma aproximação significativa que propicie uma leitura crítica e sensível dos valores, ideias, crenças, produçóes e representaçôes da pluralidade de culturas presente no espaço urbano, o que requer uma reorganizaçáo dos tempos, espaços e recursos dos bens patrimoniais.

Para tanto, é preciso diminuir o estranhamento que muitas pessoas têm com relação a alguns bens patrimoniais, em especial dos que estão inseridos em espaços/instituiçóes que os preservam, que por sua organização e estrutura se impóem de forma a inibir o acesso de boa parte da população, geralmente presentes em museus, centros culturais, bibliotecas etc.

Entre os fatores inibidores do acesso aos bens patrimoniais mais tradicionais, podemos destacar a questáo da localizaçáo das instituiçóes, visto que boa parte delas estão em regiốes centrais das cidades, que dificultam o acesso de muitas pessoas, como também o custo para frequentar estes espaços, que comumente cobram pelo acesso, e, em algumas situaçôes, com valores para visitação fora da realidade econômica de grande parte da populaçáo.

A diminuição dos incentivos fiscais e da responsabilização do Estado com a preservação, divulgação e educação voltadas ao patrimônio cultural, fruto de políticas públicas neoliberais efetivadas nas últimas décadas em nosso país, deixaram muitas instituições culturais à mercê do capital e da sociedade do consumo.

Sob esta égide, a cultura, a arte e o patrimônio ficaram desprotegidos e acabaram promovendo, até por questão de sobrevivência, uma cultura do espetáculo, com programas, projetos e açôes que favorecem a formação de 
estereótipos, em que estabelece uma fronteira simbólica entre os que têm recursos financeiros para acessá-los, e uma separação entre os "capazes" e "não capazes" de entendê-los.

Desse modo, o patrimônio cultural mais erudito ficou disponível a uma classe social específica, tomando para si uma herança que é de todos, e que primou em se apresentar de forma inatingível e incompreensível para grande parte da população. Daí o estranhamento e a falta de identificação de muitas pessoas, visto que não os compreende e não frui de seus sentidos e significados.

Esses dilemas poderiam ser mais bem dimensionados se pensarmos em uma Educação Patrimonial como um projeto educativo que envolva a cidade como um todo, visto que as cidades possuem diversos recursos que se organizam em:

[...] ambientes e instituições pedagógicas formais, como as escolas e universidades; uma rede de equipamentos, meios e recursos estáveis, porém sem a especificidade pedagógica como objetivo principal, caso de museus, bibliotecas, entre outros; um conjunto de acontecimentos e eventos que contribuam, de forma pontual, na satisfação das necessidades da população. (GRAZIANO, 2012, p. 153).

Se por um lado temos a dificuldade de acesso aos bens patrimoniais mais eruditos para boa parte da população, por outro temos esses mesmos excluídos desvalorizados nas culturas presentes em suas comunidades. Suas expressóes, ideias, práticas e representaçóes, ricas em diversidade e criatividade, quase sempre são percebidas pelos mais eruditos, e, em muitos contextos escolares, pelos profissionais da educação, como uma "cultura menor", sendo constantemente foco de preconceitos.

Tais questóes nos desafiam a buscar alternativas para, em uma primeira perspectiva, facilitar o acesso e buscar uma formação crítica aos patrimônios mais eruditos, e, em uma segunda, que incentive e valorize as culturas locais, presentes nos bairros, comunidades etc. No entanto, vale lembrar que náo são açóes isoladas que irão reverter este quadro, que, por mais bem intencionadas que sejam, acabam se apresentando como focos com pequena abrangência em suas açóes. Necessitamos de uma política educacional e cultural consistente que envolva diversas áreas da cidade, uma vez que não basta democratizar o 
acesso aos bens culturais, pois o acesso ao patrimônio cultural envolve outras questôes, como mobilidade urbana, ampliação da comunicação para tornar comuns os programas, projetos e açóes, entre outros.

Também importante é descentralizar os espaços culturais, sendo uma interessante alternativa os "Pontos de Cultura", política pública instituída desde 2004 pelo Governo Federal, que estabeleceu novos parâmetros para a gestão e democratizaçáo da cultura. Sáo implantados por meio de convênios, que procuram respeitar a dinâmica e identidade das entidades conveniadas, sendo essas de diversas naturezas, como Organizaçóes Não Governamentais (ONGs) voltadas para projetos socioeducativos, associaçóes de moradores, grupos de teatro, núcleos de extensão universitária, proposta em que as:

[...] organizaçôes culturais da sociedade que ganham força e reconhecimento institucional ao estabelecer uma parceria, um pacto com o Estado. Aqui há uma sutil distinção: o Ponto de Cultura náo pode ser para pessoas, e sim das pessoas, deve constituir-se em organizador da cultura no nível local, atuando como um ponto de recepção e irradiação de cultura. (TURINO, 2006, p. 24).

Os Pontos de Cultura são espaços para a organização e desenvolvimento de ações culturais locais, mais próximos das pessoas, o que propicia o protagonismo e o desvelar de patrimônios materiais e imateriais das comunidades. Essa experiência pode ser adequada em cada município, de acordo com a realidade local e com articulação com outras instituiçóes culturais que trabalham com bens patrimoniais, para estabelecer parcerias, e com instituiçôes de educação formal, para facilitar o acesso e a fruição dos educandos a essa produção, bem como para produzir cultura e se fazer presentes nesses espaços.

\section{Educação e patrimônio em uma cidade educadora: Guararema Cidade Natal}

Cabezudo (2004) considera que a cidade, com as diversas dimensões que a constitui, favorece aprendizagens de novas linguagens e propicia oportunidades para o conhecimento do mundo, que impulsionam o enriquecimento individual e a busca de soluçóes solidárias e humanizadas, visando à superação dos dilemas e problemas do mundo contemporâneo. 
Segundo a autora, a proposta de cidade educadora nasce da percepção de que a formação das crianças, jovens e adultos transcende a ação de instituições tradicionais, como a família, a escola e o Estado, que até então seriam as responsáveis pela educação das pessoas, tarefa essa que na atualidade também deve ser assumida pelo município, por instituiçôes e empresas, que contemple o desenvolvimento de programas, projetos e açóes educadoras.

Nessa circunstância, as cidades devem ser consideradas:

[...] como verdadeiros espaços de aprendizagem, organizando, sistematizando e aprofundando o conhecimento informal que adquirimos dela espontaneamente na vida cotidiana, $\mathrm{e}$ ajudar a descobrir relaçóes e a estrutura ou estruturas que com frequência não se mostram diretamente perceptíveis. (CABEZUDO, 2004, p. 31).

A cidade de Guararema fica a $88 \mathrm{~km}$ da cidade de São Paulo e, segundo Aureliano Leite (apud GUARAREMA, [2013]), em 1560, Braz Cubas embrenha-se pelo sertáo e descobre ouro em vasta sesmaria que chega quase à margem esquerda do Rio Anhembi (Tietê). A regiáo, que leva o nome do rio Tietê, cresceu e se desenvolveu em vários municípios. Andando-se em sentido oposto ao fluxo do rio, atravessando-se a Serra do Itapety, encontra-se o vale do Paraíba e o município de Guararema, considerado um dos melhores climas do Brasil que cresceu às margens do também grande rio Paraíba do Sul, que deságua no mar, no Estado do Rio de Janeiro. Guararema, pela exuberância do patrimônio ambiental, tem potencial turístico e histórico.

A diversidade cultural é o grande desafio para a cidade educadora. Em Guararema, assim como em qualquer cidade do interior, existem aqueles que têm uma visão da cidade, como local de refúgio, de paz, de sossego, já o poder local resolveu investir na captação e transformação dos resíduos sólidos, criandose novas possibilidades de gerar emprego e renda, além de fomentar o turismo na época do Natal e final de ano.

Há muitos fatores que precisam ser desvelados, pois muitos espaços, edificaçóes, objetos descartados ou não, por si só não se apresentam em sua totalidade, relevância e significação histórica, social e afetiva que os constituem, o que proporciona uma rica gama de possibilidades de aprendizagens, com a produção de sentidos e significaçóes que se expandem quando apresentados com uma intencionalidade educadora. 
O projeto Guararema Cidade Natal procura o diálogo entre a educação formal, preservação do meio ambiente, e a não formal de valorização de uma atração turística: os enfeites de natal da cidade, tal como é feito em Gramado, no Rio Grande do Sul. Esta última promove também o Festival Nacional de Cinema, o que traz à cidade grande impacto econômico.

Em Guararema, durante todo o ano, as escolas e a sociedade se mobilizam para arrecadar garrafas pet, "tirar lixo do meio ambiente e levar o brilho do Natal para milhares de turistas" (GUARAREMA, [2013]). O projeto parte do princípio da conscientização ambiental nas escolas e na sociedade, também promove uma atração turística, além da geração de emprego e renda.

Segundo informaçóes extraídas do site ${ }^{1}$ da prefeitura do município, das redes sociais, de vídeos da rede social youtube, nos diversos canais da mídia local e regional e usuários comuns, o projeto Guararema Cidade Natal caminha segundo modelos de outras cidades turísticas brasileiras, onde em média 300 mil garrafas pet são transformadas em decoraçóes natalinas.

Os estudantes da rede municipal são conscientizados para a captação das garrafas pet e posterior reuso em artesanato. A cada ano, um tema é escolhido, com o objetivo de se aproveitar resíduos sólidos, gerando emprego, renda e conscientização da população para a gestão do lixo e do patrimônio cultural, nenhum objeto decorativo é descartado, eles serão reutilizados no próximo natal, e assim por diante.

Para Melo e Bonini (2012), há uma ressignificação de materiais, o que era lixo se transforma em objeto de decoração do sagrado. No resultado do descarte do consumismo, os objetos se ressignificam e despertam a consciência da preservação: "Reflexo dos discursos das políticas públicas de sustentabilidade mais recentes, a reutilização do lixo deve/pode ser uma perspectiva social, de geração de emprego e renda e de qualidade de vida e, consequentemente, de consolidação da cidadania” (MELO; BONINI, 2012, p. 89).

Cabezudo (2004, p. 31) destaca a necessidade de aprender a ler a cidade e reconhecê-la como um sistema dinâmico e em evolução permanente, o que exige uma nova postura que vislumbre, além do aspecto visual da cidade como habitat concreto de cada um, e que proporcione uma possibilidade de leitura crítica e sensível para o entendimento das ideias, valores e comportamentos, que se revelam na convivência das pessoas com o espaço da cidade em que estão inseridas. 
Debord (2003, p. 10) afirmava que a "realidade surge no espetáculo e o espetáculo, no real". O olhar determina as vitrines, a arte urbana, o exibicionismo, pois o nosso tempo prefere a ilusão, a imagem, a aparência. $\mathrm{O}$ espetáculo como afirmação da vida (DEBORD, 2003) é aplicável ao município de Guararema, que, ao criar o espetáculo, envolve uma interface entre educação, cultura e sustentabilidade.

É por meio de uma intencionalidade educadora que aprofunda a reflexão de questóes que envolvam a cidade em suas múltiplas dimensôes, que as pessoas ampliam sua percepção e a crítica diante do local onde vivem e as relações que nele se estabelecem questóes que permeiam sua existência. Para Meneses (1992), a elaboração da memória se dá no presente e para responder às solicitaçôes do presente. É deste que a rememoração recebe incentivo, tanto quanto condiçôes para que se efetive. De acordo com o autor, são atribuídos valores cognitivos a objetos que tinham apenas um valor de uso no passado. No presente, um objeto do passado passa a constituir um novo sentido.

Assim, sentir o espaço que ocupamos e convivemos cotidianamente, entender as dinâmicas sociais, educativas, econômicas e culturais que nele se apresentam e que constituem sua realidade, são questôes fundamentais para uma educação cidadã e para o desenvolvimento do sentimento de pertencimento e de corresponsabilidade para com a cidade.

Segundo Bauman (2012, p. 44, grifo do autor), não se pode pensar em identidade quando o pertencimento vem naturalmente, sem luta, sem reivindicação, sem defesa ou quando "se pertence seguindo apenas os movimentos que parecem óbvios simplesmente pela ausência de competidores". Para esse autor, a marca da pós-modernidade é a ampliação do volume e do alcance da mobilidade e, por conseguinte, de forma inevitável, o enfraquecimento da influência da localidade e das redes locais da interação.

Os princípios apresentados por Cabezudo (2004) sobre a dimensão educadora na cidade revelam as múltiplas possibilidades de se proporcionar um diálogo efetivo entre os saberes escolares com a cultura local, expressado pelos modos de ser, de organizar a vida, os sentimentos partilhados pelas diversas culturas manifestas pela organização, ocupação e utilização dos tempos, espaços e recursos, das formas como se relacionam entre si, com o meio etc.

A gestão da memória, para Meneses (1992), teve início com a linguagem, passando pelo corpo, pelas cerimônias, em seguida para os objetos materiais. 
Atualmente, embora ainda incipiente, a gestão de bens materiais vem despontando em compromissos científicos e exigências políticas.

Valecillo (2009), por usa vez, afirma que novos paradigmas de gestão do patrimônio cultural necessitam incluir a participação dos cidadãos, num diálogo constante, para o empoderamento das comunidades e a transformação das políticas culturais.

\section{Considerações finais}

O objetivo deste traçado foi apontar caminhos para a educação patrimonial como um campo emergente na gestão dos patrimônios culturais, uma vez que dela decorrem novas formas de olhar o patrimônio cultural. $\mathrm{O}$ paradigma emergente da gestão cultural no Brasil é recente, já que as políticas sociais vêm sendo prioridade nos últimos vinte e cinco anos de fortalecimento da democracia brasileira, mas percebe-se, pelos resultados aqui apresentados, que questóes inovadoras pululam em algumas cidades que se prestam ao papel de liderar o debate sobre o seu papel de educadora nas questóes culturais.

Assim também, busca-se cada vez mais debruçar-se a um olhar interdisciplinar sobre a gestão de patrimônio cultural, já que é possível realizar uma abordagem sobre o patrimônio cultural a partir de uma perspectiva da sustentabilidade, se houver um projeto adequado para reaproveitamento de resíduos sólidos, como no exemplo do município de Guararema, SP, e outras cidades brasileiras que optaram por fortalecer o turismo apostando na intersetorialidade das políticas públicas: ao se integrar diferentes secretarias a fim de promover uma maior integração entre os cidadãos.

Percebe-se ao longo das pesquisas sobre patrimônio cultural que o advento de novas tecnologias vem garantindo o modo de armazenamento e divulgação de registros culturais, o que possibilita analisar mais detidamente materiais que buscam a preservação de bens culturais materiais e imateriais. Essas atitudes reforçam estratégias de ensino e aprendizagem na área da educação patrimonial, bem como auxiliam as novas abordagens de gestão cultural.

A Educação Patrimonial se apresenta como uma importante ferramenta na formação cidadã das novas geraçôes, mas, para que cumpra este papel, necessita de uma ação educativa que transcenda o espaço escolar, que seja de responsabilidade de todos os segmentos da cidade que se relacionam com os bens 
culturais, como também que envolva outras instituiçóes que possam favorecer os processos de apropriação crítica do patrimônio pelas novas geraçóes.

Assim, a Educação Patrimonial associada ao conceito de uma gestão cultural adequada, com a organização dos tempos, espaços e recursos de educação formal e não formal, constituem-se como uma possibilidade de proporcionar aos educandos processos de significação perante os bens culturais, superando a perspectiva de mera assimilação e contemplação que permeiam os processos educativos em muitas instituiçôes escolares e culturais.

$\mathrm{O}$ patrimônio cultural requer uma educação que desenvolva nos educandos posturas críticas, sensíveis referentes a este rico universo de sentidos presentes em sua vida cotidiana e que nem sempre são percebidos em suas formas de pensar e agir cotidianos. É nesse sentido que a Educação Patrimonial colabora para o desenvolvimento de um olhar crítico frente aos bens culturais que constituem as cidades, os bairros, regiôes e do país, o que favorece o desenvolvimento de um sentimento de pertencimento e de identificaçáo com esta imensa gama de representaçóes presentes no patrimônio cultural e de posturas de corresponsabilidade para sua manutenção e preservação.

\section{Nota}

1 Disponível em: <http://www.guararema.sp.gov.br/692/ guararema+cidade+natal/>. Acesso em: 29 ago. 2015.

\section{REFERÊNCIAS}

BAUMAN, Zygmunt. Ensaios sobre o conceito de cultura. Tradução de Carlos Alberto Medeiros. Rio de Janeiro: Zahar, 2012.

CABEZUDO, Alícia. Cidade educadora: uma proposta para os governos locais. In: GADOTTI, Moacir; PADILHA, Paulo Roberto; CABEZUDO, Alícia. Cidade educadora: princípios e experiências. São Paulo: Cortez; IPF, 2004. p. 11-44.

CHAUÍ, Marilena. Cidadania cultural: o direito à cultura. São Paulo: Fundação Perseu Abramo, 2006. 
DEBORD, Guy. A sociedade do Espetáculo. São Paulo: Ebooks Brasil, 2003. Disponível em: <http://www.ebooksbrasil.org/adobeebook/socespetaculo. pdf>. Acesso em: 5 out. 2014.

GOMES-GRANELL, Carmen; VILA, Ignácio. A cidade como projeto educativo. Porto Alegre, RS: Artmed, 2003.

GRAZIANO, André T. Paisagem educativa: um ensaio sobre o uso da paisagem como ferramenta educativa. In: FERNANDES, Renata Sieiro; GROPPO, Luís Antonio; PARK, Margareth Brandini (Org.). Cidade: patrimônio educativo. Jundiaí, SP: Paco Editorial, 2012. p. 143-158.

GUARAREMA. O projeto Guararema Cidade Natal. Prefeitura de Guararema, [2013]. Disponível em: <http://www.guararema.sp.gov.br/692/ cidade+natal/>. Acesso em: 23 out. 2013.

HALL, Stuart. A identidade cultural na pós-modernidade. Rio de Janeiro: DP\&A, 2006.

HORTA, Maria de Lourdes P. et al. Guia básico de Educação Patrimonial. Brasília: IPHAN/ Museu Imperial, 1999.

LIBÂNEO, José Carlos. Democratização da escola pública: a pedagogia crítico-social dos conteúdos. São Paulo: Loyola, 1999.

MCLUHAN, Marshall. Os meios de comunicação como extensóes do homem. São Paulo: Cultrix, 1974.

MELO, Eliana M.; BONINI, Luci. Mendes. Criatividade na cultura popular: a semiótica das políticas públicas de sustentabilidade. Acta Semiótica et Linguistica, São Paulo, v. 7, n. 2, p. 80-89, 2001.

MENESES, Ulpiano T. Bezerra. A história cativa da memória? Para um mapeamento da memória no campo das Ciências Sociais. Revista Instituto de Estudos Brasileiros, São Paulo, n. 34, p. 9-24, 1992.

PAULO NETTO, José. Crise do socialismo e ofensiva neoliberal. São Paulo: Cortez, 2012.

OLIVEIRA, Fabiana de; WENCESLAU, Franclin F. Educação Patrimonial e a pesquisa arqueológica do sítio "Casa de David Carrabarro". In: SOARES, André Luis Ramos; KLAMT, Sérgio Célio (Org.). Educação Patrimonial: teoria e prática. Santa Maria, RS: Editora da UFSM, 2007, p. 23-40 
PELEGRINI, Sandra C. A. Patrimônio cultural: consciência e preservação. São Paulo: Brasiliense, 2009.

PÉREZ GÓMEZ, A. L. A cultura escolar na sociedade neoliberal. Porto Alegre: Artmed, 2001.

SETÚBAL, Maria Alice; ÉRNICA, Maurício. Por que educação e cultura? In: SETÚBAL, Maria Alice (Org.). Educação e cidade. São Paulo: CENPEC, 2006. p. 143-147.

TURINO, Célio. Ponto de Cultura: a construção de uma política pública. In SETÚBAL, Maria Alice (Org.). Educação e cultura. São Paulo: CENPEC, 2010. p. 23-31.

VALECILLO, Zaida G. Como acercar los bienes patrimoniales a los ciudadanos? Educación Patrimonial, un campo emergente en la gestión del patrimonio cultural. Passos do Turismo Y Patrimonio Cultural, Islas Canarias, v. 7, n. 2, p. 271-280, 2009. Disponível em: <http:/www.pasosonline.org/ Publicados/7209/PS0209_9.pdf>. Acesso em: 9 nov. 2013.

VILLAR, Maria Bellén Caballo. A cidade educadora: nova perspectiva de organização e intervenção municipal. Lisboa: Instituto Piaget, 2007. 


\section{Culture, citoyenneté et patrimoine culturel: les interfaces entre l'école, la ville et les politiques culturelles dans la ville de Guararema, SP}

\section{Résumé}

Cet article traite de la question du patrimoine matériel et immatériel et de leur potentiel éducatif dans la formation des étudiants à la citoyenneté dans l'éducation de base. Vise à réfléchir sur les perspectives de développement d'une éducation au patrimoine dans une ville éducatrice. Sur la base on a des études qui analysent l'éducation au patrimoine dans une perspective critique, pour surmonter la simple transmission et la contemplation des biens patrimoniales sans signification, présent dans de nombreuses propositions d'enseignement dans les établissements d'éducation formelle et non formelle, de moyen qui puisse exister la collaboration avec la gestion du patrimoine culturel. Cet article contient des réflexions sur la pédagogie du patrimoine comme un domaine émergent dans l'éducation et analyse l'expérience dans la région de l'Alto Tietê, dans la ville de Guararema. Les premiers résultats indiquent que les considérations sur l'Éducation au Patrimoine devraient être un dialogue permanent entre les connaissances, les perceptions et les expériences des étudiants et des citoyens devant les biens culturels et leurs manières d'être
Culture, citizenship and cultural heritage: interfaces between the school, the city and cultural policies in the city of Guararema, SP

\section{Abstract}

This paper addresses the issue of tangible and intangible heritage and its educational potential in formation of citizenship of basic education students. It aims to reflect on the perspectives for developing a heritage education in an educating city. This discussion is based in the Heritage Education in studies which examine education from a critical perspective, in that it exceeds the simple transmission and contemplation of the property meaningless, present in many proposals on educational institutions and formal education, and non-formal, so also there is collaboration with the management of cultural heritage. This discussion is based in studies which examine education from a critical perspective, in which it exceeds the simple transmission and contemplation of the property meaningless, present in many educational proposal in formal education, and non-formal institutions, although there is collaboration with the management of cultural heritage. This article includes reflections on heritage education as an emerging field in education and analyzes the experience in the upper Tietê, in the municipality of Guararema, in São Paulo state. The first results indicate that the considerations 
et d'agir quotidiennes, et les contenus d'apprentissage et des activités éducatives développées dans les unités scolaires et les institutions culturelles, comme un moyen de comprendre les processus constitutifs de leur identité culturelle en aident la gestion du patrimoine culturel.

Mots-clés: Éducation au Patrimoine. Ville Éducatrice. Patrimoine Culturel. of that heritage education should be an ongoing dialogue among the experiences, perceptions and participation of students and citizens about cultural property and their ways of being and acting everyday with learning contents and educational activities developed in school units and in cultural institutions as a way to understand the constituent processes of cultural identity assisting in the management of cultural heritage.

Keywords: Heritage Education. Cultural Policies. Educating City.

\title{
Francisco Carlos Franco
}

E-mail: prof.franfranco@gmail.com

\author{
Rosália Maria Netto Prados \\ E-mail: rosalia.prados@gmail.com
}

\section{Luci Mendes Bonini}

E-mail: lucibonini@gmail.com

Enviado em: 24/3/2014

Aprovado em: 8/12/2014 